\title{
Podoba reke Kolpe kot mejne reke v slovenskem časopisju: primer Slovenskega naroda I86I-I9I 4
}

\author{
Marko Zajc \\ Inštitut za novejšo zgodovino, Ljubljana \\ marko.zaj@@inz.si \\ UP FHŠ, Oddelek za zgodovino
}

\section{Uvod}

Namen prispevka je zgodovinska analiza omemb mejne reke Kolpe v osrednjem liberalnem slovenskem časopisu Slovenski narod v obdobju 18681918. Osnovna hipoteza je, da se je $\mathrm{v}$ časopisu ideološka in politična razsežnost mejne reke Kolpe prepletala $\mathrm{z}$ geografsko in okoljsko-zgodovinsko razsežnostjo. Diskurz mejne reke kot pokrajinske prvine ni ideološko in politično nevtralen, in obratno, politični diskurz mejne reke se ne more ogniti svoje navezanosti na pokrajino. $V$ članku analiziramo naslednje vidike: mejna reka Kolpa kot politični koncept, upravljanje s Kolpo (gradnja in vzdrževanje mostov, zapore in oviranje prometa na Kolpi), Kolpa kot nevarna reka in mejni spori.

Pri raziskavi je uporabljena metoda zgodovinske diskurzne analize, ki izhaja iz konstruirane narave socio-kulturne realnosti in preučuje načine, s katerimi se v zgodovinskem procesu ustvarjajo oblike vednosti. Diskurzi so vzorci reda, neločljivo povezani z oblikami moči, v katerih je organizirana socialna konstrukcija realnosti (Landwehr 2008, 96). Zakaj je za raziskovanje mejnih rek upravičena uporaba metode zgodovinske diskurzne analize? Mejne reke ne obstajajo samo v pokrajini in političnih strukturah, prisotne so tudi v medijih, kjer »živijo« lastno življenje. Diskurzivno življenje mejnih rek v kontekstu prostora in časa je ključno za razumevanje fenomena mejne reke, saj omogoča razumevanje razmerij na ravni pokrajina - politika - ideologija. Raziskava je zastavljena s perspektive dol- 
gega trajanja (1868-1918). Ne gre za totalno zgodovinsko raziskavo vseh omemb mejne reke Kolpe, temveč za študijo primera, zasnovano na načelu »zajemanja iz »bazena virov«.

\section{Predstavitev reke in meje na reki Kolpi}

Kolpa pripada črnomorskemu povodju, je desni pritok Save. Ima dežno-snežni (mediteranski) rečni režim in spada med kraške reke. Značilno zanjo je, da v kanjonu prečka visoko kraško planoto Goteniško goro in nizek kraški ravnik Belo krajino. Ker je gladina kraške vode v plitvem krasu Bele krajine blizu površja, so nižji deli zemljišč ob Kolpi vsako leto poplavljeni. Dolga je $292 \mathrm{~km}$, od tega je na $118 \mathrm{~km}$ slovensko-hrvaška mejna reka. Od sotočja s Čabranko pri Osilnici do Gribelj v Beli krajini teče po ozki dolini, kjer je ob reki le tu in tam nekoliko širša naplavna ravnica, na primer pri Osilnici, Kuželju, med Brodom na Kolpi in Slavskim Lazom, pri Dolu, Radencih in Vinici. V Beli krajini je zaradi zakraselosti površinska rečna mreža redka. Vodnata Kolpa teče po obrobju nizkega kraškega ravnika, poleg Lahinje z Dobličico pa dobiva vodo le iz izvirov tik ob strugi. Večji poplavni območji ob reki sta med Gribljami in Primostkom (skupno približno 400 ha), več na hrvaški strani med Pravutino in Zaluko Lipničko, na naši strani pa predvsem v zavoju Kolpe pod vasjo Otok. Kolpa razmeroma pogosto poplavlja, danes in v preteklosti. Ker je v Metliki vodomerna postaja od leta 1877, v Radencih pa od leta 1906, je ugotavljanje pogostosti izrednih obkolpskih poplav zanesljivejše. Največji obseg so imele poplave 6. 12. 1923, 29. 9. 1933 in 3. 12. 1966. Katastrofalne poplave pa so bile verjetno tudi leta 1711, ko je po izjemnih poplavah propadla predelovalnica železa v Čabru (Komac, Natek in Zorn 2008, 124; Plut 1986, 132).

$\mathrm{V}$ zdravorazumskih predstavah mejne reke se rečna struga in mejna črta ujemata, v pokrajini in kartografskih reprezentacijah pa so med njima lahko velike razlike. Med elementoma vlada medsebojno razmerje: mejna črta je običajno določena na podlagi rečne struge. Poleg tega lahko tudi mejna črta povratno vpliva na rečno strugo (človekove aktivnosti na reki). Zaradi meandriranja reke in erozije se reka »ne drži« struge, ki so jo kartografi/geodeti »ujeli« v določenem zgodovinskem trenutku. Mejna črta se lahko prav tako spreminja zaradi političnih/administrativnih sprememb (Zajc 2017). Reke so naravni pojavi z lastno dinamiko, ki je ljudje nikoli ne morejo povsem nadzorovati. Mejne reke so drugačne - so družbeni/politični koncepti, ki jih ljudje »lepijo« na naravne reke. Po klasični sociološki definiciji meje, ki jo je zasnoval sociološki klasik Georg Simmel, meja ni 
prostorsko dejstvo $\mathrm{z}$ družbenimi učinki, ampak družbeno dejstvo, ki se izkazuje $\mathrm{v}$ prostoru. Meje imajo dvojni značaj, so posledica historičnih/političnih procesov in so hkrati tudi ustvarjalke družbenega reda (Eigmüller in Voruba 2006, 67). Tudi mejna reka je družbeno dejstvo, vendar jo bistveno določa "naravna" reka. Zaradi naravnih fluvialnih procesov (spreminjanje struge, poplave, presihanja) mejne reke delujejo »same od sebe« in tudi "govorijo za sebe«, njihova »aktivnost« ima družbene posledice. In obratno, človeška dejavnost učinkuje na reko.

V 19. stoletju je reka Kolpa razmejevala Kranjsko (in habsburške dedne dežele) od provincialne Hrvaške (in Ogrske), vendar ne velo obdobje. Zaradi ustanovitve Ilirskih provinc je Kolpa leta 1809 izgubila status mejne reke. Takšno stanje je trajalo tudi prva leta po avstrijski ponovni zasedbi. Leta 1816 je bilo ustanovljeno Ilirsko kraljestvo, ki pa nikoli ni zaživelo kot posebna upravna enota. Leta 1822 je cesar Franc zaradi ogrskih pritiskov ilirsko Hrvaško dokončno vrnil Ogrski oziroma Hrvaški. Med Kranjsko in provincialno Hrvaško se je zopet pojavila upravno-politična meja z mitnicami in s carinskimi uradi (Zajc 2006, 291). Čeprav je imela reka Kolpa mejni status skoraj na celotnem 118-kilometrskem odseku sodobne "mejne« Kolpe, pa ni razmejevala zgolj Hrvaške in Kranjske. Zaradi marindolske enklave Vojne krajine ob okljuku Kolpe jugozahodno od Metlike je do 1881. v nekaj kilometrih razmejevala tudi ozemlje vojne oblasti od p rovincialne Hrvaške. Po letu 1881 pa na tem odseku ni imela statusa mejne reke.

Narava razmejitve na Kolpi se je v 19. stoletju večkrat spreminjala. Poleg že omenjenih sprememb v začetku 19. stoletja zaradi napoleonskih vojn je narava meje na Kolpi doživela dve večji spremembi. Življenje na štajersko/kranjsko-hrvaški meji je $\mathrm{v}$ predmarčni dobi zaznamovala predvsem carinska meja med ogrskimi in ostalimi deli monarhije. V letih 1822-26 so bile med zahodnimi avstrijskimi deželami dokončno ukinjene vse carinske meje. Leta 1830 je začela delovati Kameralna uprava posrednih davkov, ki sta ji bila na Kranjskem podrejena tudi urada za obmejno carino in davek od soli v Jesenicah (na Dolenjskem) in Metliki. Pomožni uradi za obmejno carino, davek od soli in ogrsko tridesetino so bili razvrščeni vzdolž meje dežele Kranjske z ogrskimi deželami v Kostanjevici, Vinici, Osilnici, Radovici, Gaberjah, Jugorju, Pobrežju, Gribljah, Poljanah, Travi, Babnem Polju in Kermačini (Keber 2003, 27). Po letu 1836 so bili splošni pogoji prometa čez mejo določeni s posebnim monopolnim redom, ki nam odkriva, kako je razmejevanje na Kolpi potekalo v praksi (Hepe idr. 2011, 38). 
Za blago ni bilo potrebno imeti posebnega dovoljenja, razen za predmete državnega monopola, kot so kuhinjska sol, tobak in smodnik. Za popotnike, ki so imeli tuj tobak za osebno uporabo, ga je bilo dovoljeno prenesti brez posebnega dovoljenja za pet dunajskih funtov (pribl. 2,8 kg). Zanimive so izjemne situacije, $\mathrm{v}$ katerih je lahko potekal promet po stranskih cestah skozi mejno črto. Živo živino je bilo dovoljeno spraviti čez mejo na pašo ali zaradi opravljanja kmečkih del, pod pogojem, da se jo je še isti dan privedlo nazaj. Transport blaga preko meje pa ni smel potekati pred sončnim vzhodom in po sončnem zahodu (Zoll- und Staats- MonopolsOrdnung 1835). Ker je bilo trgovanje s tobakom (od leta 1690) v avstrijskih deželah monopol, v ogrskih pa ne, je bil ogrski zaradi tega občutno cenejši. Zaradi prepovedi je lahko potrošnik dobil ogrski tobak v slovenskih deželah samo s pomočjo nelegalnega posrednika - tihotapca. Ta posel je cvetel vse do srede petdesetih let 19. stoletja, ko je bila carinska meja dokončno odpravljena.

Za drugo večjo spremembo statusa meje na Kolpi pa je bila odgovorna uvedba državnega dualizma leta 1867. Kolpa je poslej ločevala dve samostojni državni "polovici«, ki sta bili povezani s skupno zunanjo politiko, financami in z vojsko. Na Dunaju so dualistično državo razumeli kot »zvezno državo«, utemeljeno na personalni in realni uniji. Skupne institucije naj bi dokazovale državno enotnost, zato so jim na Dunaju pripisovali odločilno vlogo. Ogrska stran pa je v skupnih institucijah videla zgolj rezultat svobodne volje dveh suverenih držav, da skupno urejata določene zadeve (Cvirn 2015, 119). Državna ločenost je imela tudi praktične posledice. Kot je zapisal sourednik slovenskega naroda Josip Jurčič leta 1870 v znamenitem članku »Slovenci in Hrvati«, je Hrvaška onstran Kolpe z dualizmom postala tujina. Po dualizmu so se končale migracije, povezane s šolstvom, saj po tem datumu ogrske izobraževalne ustanove niso bile veljavne v avstrijskem delu monarhije in obratno (Jurčič 1982, 379)

\section{Kolpa kot element ideološkega povezovanja}

Časopis Slovenski narod (1868-1945) je zaradi trajnosti ter nacionalistične in liberalne usmerjenost primeren za historično analizo omenjanja reke Kolpe kot mejne reke v daljšem trajanju. Ustanovili so ga večinoma liberalno usmerjeni slovenski narodnjaki, ki so poskušali v obdobju po uvedbi dualistične ureditve monarhije in po sprejetju decembrske ustave razvijati aktivno slovensko politiko $\mathrm{v}$ razmerah habsburškega parlamentarizma. Slovenski narod je postal prvi trajni politični časopis s slovenskim pred- 
znakom, ki je le štiri leta po nastanku postal tudi prvi slovenski dnevnik (Vatovec 1968, 10).

Kolpa (podobno kot Sotla) na straneh Slovenskega naroda ni bilo zgolj lastno ime za reko, ampak predvsem simbol naravne meje med Slovenci in Hrvati. Pojavljala se je tudi v člankih, ki s samo reko niso imeli nobene povezave. Sintagma »onstran Kolpe« je preprosto pomenilo hrvaško ozemlje. To opredeljevanje s pomočjo mejne reke pa ni bilo vrednostno nevtralno. Slovanstvo in jugoslovanstvo sta bila integralni del tedanje slovenske nacionalne ideologije. $\mathrm{V}$ slovenskem vrednostnem sistemu tistega časa je Kolpa meja, ki je in ni, ki povezuje in ločuje, oziroma meja, ki bolj povezuje kot ločuje. Hrvati (in južni Slovani nasploh) so bili obravnavani kot zavezniki in »bratje« po krvi (Zajc 2012, 105). Mejo na Kolpi so v obravnavanem obdobju v liberalnem časopisu praviloma obravnavali kot nepotrebno nadlogo in oviro za jugoslovansko povezovanje. Žalostno usoda je na Kolpi in Sotli naredila močan jez, je zapisal Slovenski narod julija 1878, »ter s tem razdvojila najbližnje si brate v dva, češ da različna naroda«. »Zgodovina nas uči, « je zatrdil pisec, »da nij sile, katera bi narode bolj razločevala, nego li državna meja« (SN 1878a, 1). Za ustvarjalce Slovenskega naroda pa je bila ta razdvojevalna sila šibkejša kot povezovalni elementi. Začasni urednik časopisa Ivan Tavčar je leta 1880 v Zagrebu zatrdil, da mu vedno, ko prestopi reko Kolpo, začne biti srce hitreje, saj je prestopil mejo svoje ožje domovine in prišel v hišo gostoljubnega brata po krvi, ki živi (zaradi hrvaške avtonomije) v svobodnejših razmerah ( $\mathrm{SN}$ 188oa, 2). Ko so slovenski poslanci v kranjskem deželnem zboru oktobra 1878 cesarja ponovno prosili za združenje Slovencev v eno politično enoto (Zedinjeno Slovenijo), so za zamejevanje svojega ozemlja uporabili tudi reko Kolpo. Slovenija naj bi se raztezala od Drave in Mure do Jadranskega morja ter od Triglava do Sotle in Kolpe $(\mathrm{SN} 1878 \mathrm{~b}, 1)$.

Tako kot Sotla tudi Kolpa ni bila zgolj simbolna meja s Hrvati, bila je prostor, kjer se je slovenstvo srečevalo z jugoslovanstvom - včasih dobesedno. Ko so v Vinici slovenski narodnjaki oktobra 1891 slavnostno odpirali čitalnico, se je prireditve udeležila tudi obsežna hrvaška delegacija. $\mathrm{Na}$ dan slovesnosti so organizatorji v spremljavi črnomaljske mestne godbe hrvaške goste pričakali kar na mostu na Kolpi: »Na sredini mosta, kjer meji Kolpa Hrvatsko od Kranjske pozdravijo slovenska društva brate Hrvate.« $(\mathrm{SN} 1891,2)$ Jugoslovanski navdušenci pri Slovenskem narodu so leta 1898 običajen izlet hrvaških turistov na kranjsko stran Kolpe opisali kot manifestacijo jugoslovanske solidarnosti. Hrvaški gosti, ki so prišli na kranjsko 
stran s čolni, naj bi v slovensko čast prepevali zgolj slovenske pesmi (SN $1898,2)$.

\section{Upravljanje z mejno reko Kolpo}

Bližina reke od ljudi terja določene aktivnosti. Dejstvo, da je reka mejna, dodatno zaplete izvajanje teh aktivnosti: kdo ima pristojnosti do posegov? Kdo financira aktivnosti? Kdo jih izvaja? Izvajanje aktivnosti terja komunikacijo in usklajevanje med dvema entitetama, ki jih reka razmejuje. Zaradi težav $z$ uskladitvijo in s financiranjem del oblasti $z$ obeh strani meje pogosto zavlačujejo z deli na škodo obmejnega prebivalstva na obeh straneh. Deželni poslanec Savischegg (tudi Zavinšek), sicer metliški posestnik in pripadnik »nemške « ustavoverne stranke, je 4. decembra 1872 v Kranjskem deželnem zboru na vlado naslovil interpelacijo glede gradnje mostu na Kolpi. Savinschegg je vladi predstavil slabe prometne povezave Bele krajine s Hrvaško. Edini most, ki je povezoval hrvaški in kranjski breg reke Kolpe, je stal pri Metliki. Od Metlike naprej v smeri toka reke Kolpe pa v dolžini 11 milj ni bilo nobenega mostu. Hrvaški posestniki so sicer pri Gribljah in Vinici uredili "primitivno urejen brod", ki je na voljo vsem, ki prečkajo reko, vendar ta brod ni pritrjen z žicami in ga je ob visokih vodah odnese reka. Za Vinico je ta odrezanost od Hrvaške še toliko bolj boleča, ker se $\mathrm{v}$ neposredni bližini na hrvaški strani nahaja prometna povezava med Karlovcem in Reko, do katere imajo Viničani (če lahko pridejo čez Kolpo) dvajset minut. Omenjena cesta je za prodajanje viniških produktov ključnega pomena, je bil jasen Savinschegg. Karlovec, kjer vsak teden poteka živinski sejem, lahko Viničani dosežejo z živino v štirih urah - pod pogojem, da lahko prečkajo reko pri Vinici. V primeru visokih voda to ni mogoče, takrat potrebujejo do Karlovca več kot devet ur. Obenem je Savischegg opozoril, da imajo brod pri Vinici in Gribljah v posesti hrvaški lastniki in da lahko Belokranjci prečkajo Kolpo zgolj z njihovim dovoljenjem. Zato je prosil vlado na Dunaju, naj se prične pogajati s hrvaško vlado glede premostitve Kolpe pri Gribljah in Vinici (OKDZ 1872, 9, 90). Deželni predsednik (predstavnik centralne vlade v deželi) mu je odgovoril, da je zadeva sicer lokalna, vendar pa jo je vlada pripravljena podpreti (SN 1872, 1).

Zastavljeni infrastrukturni projekt je zahteval svoj čas. Sledila so pogajanja s hrvaško stranjo. Oktobra 1881 so kranjski deželni poslanci potrdili finančno udeležbo pri projektu. Zanimivo je, da je hrvaška stran prevzela večino stroškov gradnje. Od nekaj manj kot 40.000 goldinarjev, kolikor je bila ocenjena gradnja, je hrvaška prispevala kar 25.0oo goldinar- 
jev, medtem ko je kranjski deželni zbor izgradnji mostu namenil zgolj 7.000 goldinarjev. Ostala sredstva (8.ooo goldinarjev) naj bi prispevala lokalna skupnost. Kranjski deželni poslanci so razmišljali, da bi most dali najem podjetniku, ki bi nekaj let pobiral mostnino. To opcijo so zavrnili kot dražjo. Glede na to, da gre za revno področje, bi si prebivalci mostnino težko privoščili (SN 1881a, 2).

125 metrov dolg most čez Kolpo pri Vinici je bil slovesno blagoslovljen 15. oktobra 1885. Temelje so položili že leta 1883 , vendar je gradnjo oviralo slabo delo. Gradnjo so zaupali hrvaškemu podjetniku, dela je vodil hrvaški strokovnjak, sodeloval pa je tudi kranjski inženir. Slovenski narod piše, da je bil za izgradnjo mostu najzaslužnejši ugledni domačin J. Stariha, ki je zavzeto lobiral za most tako v Ljubljani kot v Karlovcu in Zagrebu. Ne glede ne želje kranjskih poslancev pa mostu ni bilo mogoče dokončati brez udeležbe bodočih uporabnikov. Pobiranje mostnine so oddajali v najem za tri leta. Že omenjeni dobrotnik Stariha pa je ob otvoritvi mostu oznanil, da je do začetka leta 1886 plačal uporabo mostu »za ljudstvo« iz lastnega žepa. Poročilo v Slovenskem narodu o slovesnosti v Vinici lepo prikazuje, kako se simbolna razsežnost poveže s praktičnimi razlogi. Za slovesnost so most s kranjske strani okrasili s cesarskimi in slovenskimi zastavami, s hrvaške strani pa s kraljevimi ogrskimi in hrvaškimi zastavami. Prijateljstvo med narodoma so izrazili $z$ nenavadnim ritualom: na slovesnosti je šest hrvaških in šest kranjskih mož v znak prijateljstva kadilo iz iste pipe (SN 1885, 2). Most je bilo treba tudi vzdrževati. Slovenski narod je julija 1902 poročal, da je Kranjska za popravilo mostu v Vinici obvezana plačati 16.340 kron, od tega naj bi lokalna skupnost plačala $24 \%$ (SN 1902a, 1).

Kolpo je bilo kot mejno reko med obema polovicama države potrebno premostiti tudi za potrebe železniškega prometa. Bela krajina je bila relativno prometno izolirana, zato so na Kranjskem prizadevanja za izgradnjo belokranjske železnice pričela že leta 1864 . Za povezavo Novega mesta s Karlovcem so bili zainteresirani tudi na Hrvaškem, prav tako je progo podpiralo vojno ministrstvo zaradi neposredne povezave $s$ strateško izpostavljeno Dalmacijo. Progi pa so nasprotovali ogrske oblasti in tržaški gospodarski krogi. Izgradnja proge je bila predvsem odvisna od pogajanj med avstrijsko in ogrsko polovico države. Po pogajanjih med Dunajem in Budimpešto $v$ letih 1906-7 je gradnja belokranjske proge končno dobila zeleno luč. Avstrijska stran je pristala na izgradnjo karpatske proge (KošiceBohumin), Ogrska pa se je obvezala zgraditi povezavo čez hrvaško ozemlje (od Karlovca in Ogulina do Knina, Rustja 1994, 97). 
Po dolgih peripetijah na relaciji Dunaj - Budimpešta in po lokalnih prepirih o natančni trasi proge so pričeli z gradnjo proge aprila 1912. Pomemben del projekta je bil železniški most pri Metliki. Most je bil dolg 80 metrov, 432 ton težka jeklena konstrukcija je slonela na dveh opornikih, ki sta segala 18 metrov globoko (Rustja 1994, 105). Slovenski narod o gradnji mostu ni veliko pisal. Februarja 1908 je časopis poročal, da se bo čez Kolpo pri Metliki gradil železni most in da bo v Metliki mejni kolodvor. Glede zveze s hrvaško progo pa takrat še ni bilo natančnega dogovora (SN 1908, 5). Proga je bila končana tik pred začetkom prve svetovne vojne 1914. Pri prizadevanju za gradnjo se je še zlasti odlikoval politik Fran Šuklje, ki je pred tem iz liberalnega prestopil v katoliški tabor. Ker je pred prvo svetovno vojno vladala na Kranjskem vladala katoliška stranka, liberalni časopis Slovenski narod ni razglašal njihovega velikega uspeha - izgradnje belokranjske železnice in povezave s Hrvaško. Slovenski narod je predvsem opozarjal, da si katoliški politiki izgradnjo železnice lastijo kot svojo zaslugo, čeprav naj s tem državnim podjetjem ne bi imeli nobene zveze (SN 1914, 1).

Dogajalo se je tudi, da sta Kranjska in Hrvaška z vzdrževanjem mostov na Kolpi pričeli šele takrat, ko so mostovi postali neprehodni. Februarja 1909 so zaprli most na Brodu na Kolpi, »ker je že tako slab, da se lahko v kratkem podere«. Nov most naj bi začeli graditi spomladi, stroške pa naj bi si Kranjska in Hrvaška razdelili na pol (SN 1909, 2). Železobetonski most so res zgradili, vendar se je Slovenski narod pritoževal, da je napis na mostu v tako slabi slovenščini, da ga nihče ne razume ( $\mathrm{SN}$ 1910, 3). Najverjetneje je šlo za bivši privatni most, ki so ga kranjske in hrvaške oblasti leta 1881 prevzele v skupno lastnino in vzdrževanje ( $\mathrm{SN}$ 1881b, 2)

\section{Zapore in oviranje prometa na Kolpi}

Meja na Kolpi je bila prehodna, vendar so jo oblasti občasno zaprle zaradi nalezljivih bolezni. Junija 1874 se je dopisnik iz Črnomlja pritoževal, da je v njihovem okraju že dve leti v veljavi zapora prometa na Kolpi, čeprav živinske bolezni že davno ni več (SN 1874, 3). Ko se je leta 1879 pojavila bolezen živine na Hrvaškem, so oblasti na Kranjskem določile, da morajo lokalni kmetje sami stražiti ob reki Kolpi, da bi preprečili nelegalno trgovanje z živino. Straže so določili župani, nadzorovala pa jih je žandarmerija (SN 1879, 2). Že naslednje leto se je na Hrvaškem ponovno pojavila goveja bolezen. Črnomaljsko okrajno glavarstvo je določilo, da je prestop deželne meje mogoč le preko mostu v Metliki in preko broda $\mathrm{v}$ 
Vinici, seveda s potrebnimi dokazili. Oblasti so poskušale nadzorovati tudi vodni promet na reki Kolpi. Ukazale so prikleniti vse čolne in brodove, vesla pa so zasegli občinski predstojniki (SN 188ob, 1). Ko je leta 1886 na Hrvaškem izbruhnila kolera, so kranjske oblasti prepovedale udeležbo Hrvatov na cerkvenem praznovanju v znanem romarskem središču Tri fare pri Metliki (SN 1886, 3).

Čeprav je dualistični sporazum leta 1867 potrdil odpravo notranjih carin, kar naj bi spodbudilo svobodno trgovino med avstrijskim in ogrskim delom države, pa blagovni promet med državnima polovicama ni potekal povsem svobodno. Še zlasto Ogrska se je pogosto posluževala netarifnih konkurenčnih ovir, da bi zaščitila lastno gospodarstvo. Mehanizmi za oviranje svobodne trgovine med Cis- in Translajtanijo so bili raznoliki: različne tranzitne dajatve, železniške tarife, prepovedi uvoza, inovativna uporaba predpisov, državne pomoči in subvencije. Ti ukrepi so vplivali na cene dobrin podobno kot zaščitne carine, čeprav to $\mathrm{v}$ strogem pomenu besede niso bile (Schall 2001, 151). Meja na reki Kolpi je torej lahko pomenila tudi mejo med različnimi cenami dobrin ali mejo za opravljanje določenega posla.

O ogrskih ovirah za svobodno trgovino na meji s Hrvaško je poročal tudi Slovenski narod. V kranjski vasi Osilnica so imeli težave zaradi meje na Kolpi leta 190o. V vas je bilo mogoče $\mathrm{z}$ vozovi priti samo preko hrvaškega ozemlja. Ko je ogrska vlada leta 1900 napovedala prepoved uvoza sladkorja v dežele pod ogrsko krono, so v Osilnici ugotavljali, da bodo imeli velike težave. »Kaj naj potem napravijo naši trgovci! Od kod naj dobijo sladkor? Najbližji kolodvori ležijo tako, da se mora iti po Hrvatskem. Naj li trgovci nosijo na hrbtu sladkor iz Kočevja? « Dopisnik je še predlagal, naj se vladi dogovorita za recipročnost: Kranjcem naj se dovoli uporaba hrvaške, Hrvatom pa uporaba kranjske ceste (SN 1900, 4). Dve leti kasneje težav še niso rešili. Januarja 1902 je Slovenski narod objavil komentar o avstrijski finančni politiki, ki naj bi bila kruta do domačih podjetnikov. Za vzor bi si morali vzeti ogrsko vlado, ki odkrito ščiti in spodbuja domače gospodarstvo. Za primer je navedel Osilnico ob Kolpi, ki občasno trpi veliko pomanjkanje: »Ogrska uprava s tako krutostjo zahteva od naše strani spolnjevanje vseh določil, da $\mathrm{v}$ to občino ne prineseš niti litra piva ali kile sladkorja. Če ga prej na Ogrskem ne obdavčiš.» Če kupi Hrvat na Kranjskem kilogram mesa, mu hrvaški finančni stražniki meso vzamejo in ga vržejo v vodo (SN 1902b, 1). 


\section{Kolpa kot nevarna reka}

Ne glede na mejni status je bila reka predvsem naraven fenomen z lastno dinamiko. Reka je lahko tudi nevarna. Čeprav Kolpa ne velja za reko, ki veliko poplavlja, pa je na nekaterih mestih redno prestopala bregove. Tako je v začetku septembra 1884 poplavila polja pri Metliki, ravno takrat, ko so kmetje pokosili travo za krmo živine, kar jim je povzročilo veliko škode (SN 1884, 3). Reka je bila lahko tudi življenjsko nevarna. Poleti 1873 so v Slovenskem narodu ugotavljali, da je vroče poletje mnoge prepričalo v kopanje v osvežujoči Kolpi. Čeprav je voda zdrava, pa je tudi smrtno nevarna, je opozarjal pisec, in naj bi ponovno odnesla otroka (SN 1873, 3). O utopljencih v Kolpi so v časopisu veliko poročali. Junija 1880 se je v Kolpi utopil zakonski par, ki se je s čolnom vračal $\mathrm{z}$ obiska pri sorodnikih na hrvaški strani reke, nesreči pa je botroval predvsem alkohol (SN 188oc, 3). Ko so gradili železniški most čez Kolpo, sta se proti koncu decembra 1912 dva delavca utopila v reki. Preobloženi čoln s peskom se je prevrnil, delavca pa sta v mrzli vodi utonila, čeprav sta znala plavati (SN 1912, 4). Včasih se je nesreča končala srečno. Marca 1875 se je skupina Hrvatic in Hrvatov v čolnu peljala s hrvaškega brega proti Vinici. Na sredini Kolpe se je preobteženi čoln začel potapljati. Razen dveh kmetic so vsi znali plavati, vendar so uspeli rešiti tudi neplavalki (SN 1875a, 3).

Kolpa pa ni bila nevarna samo zaradi lastne dinamike, ampak tudi zaradi človekovega delovanja, ki je bilo večkrat posledica mejnega statusa reke. Slovenski narod je leta 1875 poročal o dolgem in tragičnem sporu med kranjskimi mlinarji ter hrvaškim posestnikom na drugi strani Kolpe. Hrvaški posestnik Dimitrovič je leta 1860 s tožbo dosegel, da so oblasti kranjskim mlinarjem prepovedale gojiti ribe za jezom mlina. Poleg tega naj bi omenjeni Dimitrovič zahteval koncesijo za gradnjo mlina na hrvaški strani, in to tako, da bi porabil vodno moč kranjskih mlinarjev. Čeprav mu hrvaške oblasti tega niso dovolile, poroča Slovenski narod, je pričel z gradnjo mlina. Sovraštvo je raslo, prihajalo je do pretepov in groženj s smrtjo. Do tragičnih dogodkov je prišlo marca 1875 , ko so kranjski mlinarji ribarili v Kolpi z dovoljenjem hrvaškega grofa. Nenadoma se je prikazal Dimitrovič in začel na njih streljati z revolverjem. Kranjski mlinarji so ga kljub temu obvladali in zbili na tla. Maščevanje je bilo strašno. Besni nasprotniki so ga pretepali, dokler ni mrtev obležal v krvi (SN 1875b, 3).

Septembra 1911 se je ob Kolpi zgodil grozljiv umor, ki bi ga lahko opredelili kot lokalno različico linča. Čeprav zločin ni bil povezan z razmejevanjem ob reki, pa je imela Kolpa pri dogajanju pomembno vlogo. Po pri- 
čevanju dopisnika Slovenskega naroda je bila tragedija posledica »velikega strahu«, ki se je razširil med hrvaškim ljudstvom ob Kolpi zaradi skrivnostnih požarov. Med ljudmi so se razširile govorice, da so požigalce poslali Madžari ali pa zavarovalniške družbe. 19. septembra pa so hrvaški kmetje opazili tujca, ki se je sprehajal po poljih ob Kolpi. Ko so ga pričeli loviti, se je pognal v beg. Videl je, da jim ne bo mogel uiti, zato je skočil v reko in plaval na kranjsko stran. A to ga ni rešilo. Hrvatje so kranjskim mlinarjem naročili, naj ga primejo. Po njega so prišli s čolnom in ga odpeljali na hrvaški breg. Tam so ga zasliševali, pri čemer naj bi prednjačili možje, ki so se vrnili iz Amerike. Nesrečnik je trdil, da je Čeh iz zlate Prage, oče šestih otrok in da ne razume, zakaj so ga prijeli. Povratniki iz Amerike so drhal prepričevali, da razumejo češko in da je tujec požige priznal. Nakar se je pričel linč: drhal ga je pretepala s palicami, suvala $\mathrm{z}$ gnojnimi vilami in streljala vanj $\mathrm{z}$ revolverji. Sodelovalo naj bi več kot 300 ljudi. Pripravili so grmado iz slame in ga še živega zažgali. Dopisnik je bil zgrožen: „Če sedaj pomislim na tisti kraj, kjer leži umorjeni, me groza obletava, da se more zgoditi kaj tako nečuvenega v 2o. stoletju." Čeprav je Slovenski narod običajno poudarjal, da med Slovenci in Hrvati ni velikih razlik, pa se je v tem primeru jasno distanciral od Hrvatov: »Samo Kolpa nas deli - pa kakšna razlika.« (SN 1911, 3)

\section{Zaključek}

$\mathrm{V}$ članku sem na podlagi poročanja liberalnega slovenskega časopisa Slovenski narod v obdobju 1868-1914 prikazal štiri razsežnosti reprezentacij Kolpe kot mejne reke: 1) Kolpa kot element ideološkega povezovanja; 2) upravljanje s Kolpo; 3) zapore in oviranje prometa na Kolpi; 4) Kolpa kot nevarna reka. V pisanju časopisa o Kolpi se lepo kaže glavna značilnosti mejnih rek: neločljivo razmerje med mejno reko kot družbenim/političnim konceptom in reko kot naravnim pojavom. Mejna reka je fenomen, ki ga določata dve sferi s povsem različnima načinoma delovanja: družbena realnost in realnost narave (spreminjanje struge, poplave, presihanja). Interakcija med obema sferama ni niti preprosta niti stalna in jo lahko opredelimo zgolj v zgodovinskem kontekstu. Seveda mejna reka ni edini fenomen, za katerega to velja, je pa eden izmed najočitnejših. Prav tako je očitno, da se lahko družbena realnost manifestira zgolj v naravi. Dejstvo, da meja poteka med dvema entitetama po reki, določa tudi politično in družbeno naravo reke, in obratno, dejstvo, da ima neka reka mejni status, vpliva na njeno fizično realnost. 


\section{Viri in literatura}

\section{Objavljeni viri}

\section{OKDZ: Obravnave Kranjskega deželnega zbora}

1872, 9: 1872, št. 9, 4. 12. 1872.

\section{SN: Slovenski narod}

1872: 10. 12. 1872, let. 5 , št. 143.

1873: 17. 7. 1873 , let. 6 , št. 162.

1874: 11. 6. 1874, let. 7 , št. 130.

1875a: 24. 3. 1875, let. 8, št. 67.

1875b: 27. 6. 1875 , let. 8 , št. 144 .

1878a: 15. 7. 1878, let. 11, št. 160.

1878b: 6. 10. 1878 , let. 11, št. 230.

1879: 7. 5. 1879, let. 12 , št. 104.

188oa: 20. 12. 1880, let. 13, št. 289.

188ob: 20. 5. 188o, let. 13, št. 113.

1880c: 15 . 6. 1880 , let. 13 , št. 134 .

1881a: 5. 10. 1881, let. 14, št. 226.

1881b: 27. 9. 1881, let. 14, št. 219.

1884: 2. 9. 1884, let. 17, št. 202.

1885: 26. 10. 1885, let. 18, št. 244.

1886: 11. 8. 1886, let. 19, št. 181.

1891: 14. 10. 1891, let. 24, št. 234.

1898: 10. 5. 1898, let. 30, št. 105.

1900: 10. 2. 1900, let. 33, št. 33 .

1902a: 12. 7. 1902, let. 35, št. 157.

1902b: 31. 1. 1902, let. 35, št. 25.

1908: 8. 2. 1908, let. 41, št. 33.

1909: 23. 2. 1909, let. 42, št. 43.

1910: 17. 7. 1910, let. 43, št. 176.

1911: 22. 9. 1911, let. 44, št. 120.

1912: 31. 12. 1912, let. 45, št. 300.

1914: 28. 5. 1914, let. 48, št. 120. 


\section{Literatura}

Cvirn, J. 2015. Dunajski državni zbor in Slovenci (184-1918). Celje: Zgodovinsko društvo Celje.

Eigmüller, M., in G. Voruba, ur. 2006. Der duale Character der Grenze. Grenzsoziologie, die politische Strukturierung des Raumes. Wiesbaden: Springer.

Hepe, B., K. Janjič, S. Mikuž in I. Živko. 2011. Zgodovina carine na Slovenskem od antike do slovenske osamosvojitve. Ljubljana: Carinska uprava Republike Slovenije.

Jurčič, J. 1982. Zbrano delo, deseta knjiga, ur. M. Rupel. Ljubljana: DZS.

Keber, K. 2003. »Epidemije na Slovenskem: primer kolere v 19. stoletju.« Magistrsko delo, Univerza v Ljubljani.

Komac, B., K. Natek in M. Zorn. 2008. Geografski vidiki poplav v Sloveniji. Ljubljana: Založba ZRC.

Landwehr, A. 2008. Historische Diskursanalyse. Frankfurt na Majni; New York: Campus Verlag.

Plut, D. 1986. »Geografske značilnosti poplavnega sveta Kolpe in njenih pritokov v zgornjem Pokolpju.« Geografski zbornik 25: 125-55.

Rustja, K. 1994. Dolenjske proge: tiri in čas. Ljubljana: Železniški muzej.

Schall, G.2001.Derösterreichisch-ungarische DualismusalsIntegrationskonzept. Hamburg: Verlag Dr. Kovač.

Vatovec, F. 1968. »Ob zibeli ,Slovenskega naroda' pred sto leti.« V Ob stoletnici ustanovitve "Slovenskega naroda« 1868-1968, ur. B. Avsenak. Maribor: Društvo novinarjev Slovenije.

Zajc, M. 2006. Kje se slovensko neha in hrvaško začne: slovensko-hrvaška meja $v$ 19. stoletju. Ljubljana: Modrijan.

Zajc, M. 2012. »Sotla, majhna voda. Reka Sotla kot naravna, politična in ideološka meja v 19. in začetku 20. stoletja." Zgodovina za vse 19 (1/2): 101-13.

Zajc, M. 2017. »The Border River Phenomenon: The Example of the River Mura."Prispevki za novejšo zgodovino 57 (3): 44-65.

Zoll- und Staats- Monopols-Ordnung. 1835. Dunaj: K. k. H. Staats-Arearial-Druckerei. 


\section{Summary}

\section{The image of the river Kolpa as a border river in Slovenian newspapers: The example of the Slovenski narod 1861-1914}

The article analyses the portrayal of the Kolpa as a border river in the leading Slovene liberal newspaper Slovenski narod from 1868 to 1918. In the 19th century, the Kolpa divided Carniola (and the Habsburg hereditary lands) from Civil Croatia (and Hungary). During the pre-March period, life on the border between Carniola and Croatia was primarily influenced by the customs border between the Hungarian and other parts of the Habsburg Monarchy. A second major change in the border on the Kolpa River resulted from the 1867 introduction of state dualism. From that point onward, the Kolpa separated two independent halves of the monarchy, which shared the same foreign policy, finances, and the military. On the pages of Slovenski narod, the Kolpa River was not only a proper name denoting a river, but also and primarily a symbol of a natural border between the Slovenes and Croatians. Slavic or Yugoslav identity was an integral part of Slovene national ideology at that time. Croatians (and South Slavs in general) were considered allies and a "brother" nation. Living close to a river demands certain activities. The fact that a river also forms a border additionally complicates the implementation of these activities, which demands communication and coordination between the two entities separated by the river. The state also invested a lot of energy into controlling the border during outbreaks of various diseases, when they tried to seal the border as much as possible. The Kolpa flooded regardless of its border status, but both entities separated by the river had to deal with the floods' consequences. In one of the articles examined, the river as a natural landscape element with certain economic potentials (milling and fish farming) was at the core of a border dispute. The main characteristic of border rivers is clearly seen from the articles published in Slovenski narod: the inextricable connection between the border river as a social/political concept and the river as a natural feature. A border river is a phenomenon defined by two spheres with completely different characters: social reality and the reality of the natural environment (i.e. changes in the riverbed, floods, and intermittence). The interaction between the two spheres is neither simple nor constant, but it can be defined within a historical context. 